\title{
Датчик акустических воздействий на основе маломодовых оптических волокон
}

\author{
М.В. Дашков \\ Поволжский государственный университет телекоммуникаций и информатики \\ E-mail: $\underline{\text { mvd.srttc@gmail.com }}$
}

DOI: 10.31868/RFL2020.147-148

В ряде работ [1-3] рассматривалось применение маломодовых оптических волокон в качестве датчика внешних воздействий. В данной работе представлены результаты исследования датчика акустических воздействий, реализованного на основе оптического волокна (ОВ), функционирующего в маломодовом режиме.

Экспериментальная установка для исследования акустических воздействий на параметры излучения маломодового волокна приведена на рис. 1. В качестве источника излучения использовался лазерный диод (ЛД) с центральной длиной волны $980 \mathrm{нм}$ и выходной мощностью 5 мВт. Для управления состоянием поляризации в схему использовался контроллер поляризации (КП). Контролер модового состава (КМС) использовался для управления режимом возбуждения моды высшего порядка.

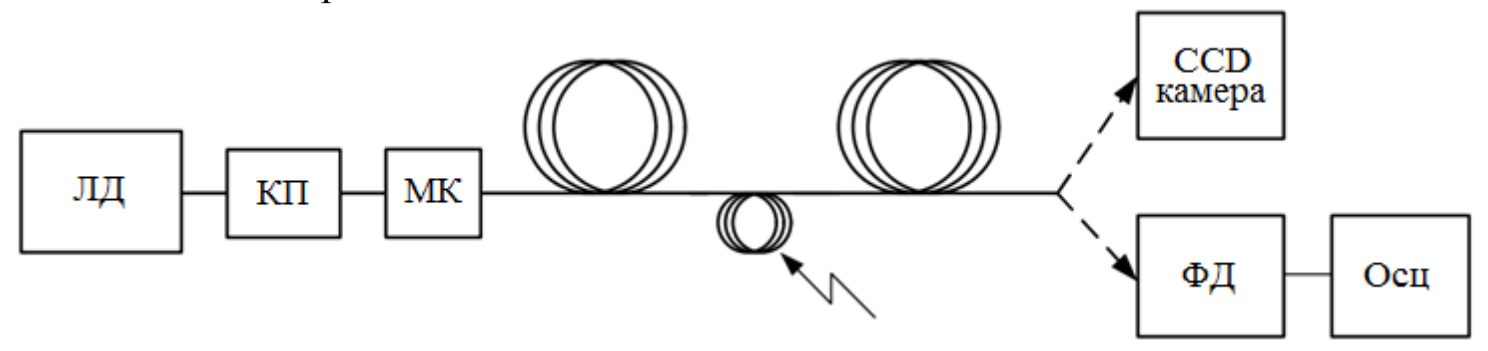

Рис. 1. Схема экспериментальной установки

В качестве сенсорного использовалось OB Corning SMF-28e+ суммарной длиной 5,9 км. На расстоянии 4,9 км участок ОВ был выведен для приложения акустических воздействий. Для детектирования использоваться p-i-n фотодиод с трансимпендансным усилителем (PD/TIA).

В результате теоретических расчетов было определено, что при использовании источника излучения с длиной волны 980 нм используемое ОВ поддерживает распространение двух мод $\mathrm{LP}_{01}$ и $\mathrm{LP}_{11}$. Для экспериментального исследования модового состава ОВ использовалась цифровая $\mathrm{CCD}$ камера. На рис. 2 приведены распределения оптического поля, полученные при различных установках модового контроллера.

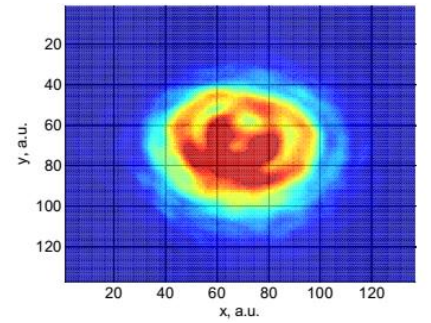

a)

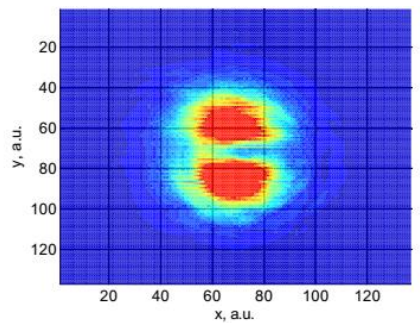

б)

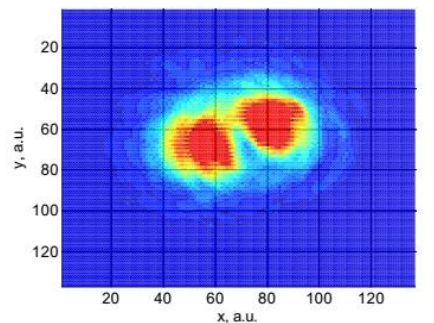

B)

Рис. 2. Распределения оптического поля, полученные при различных установках модового контроллера: a) суммарное поле; б) мода $\mathrm{LP}_{11 \mathrm{a}}$; в) мода $\mathrm{LP}_{11 \mathrm{~b}}$ 
Исследование акустических воздействий производилось при различных конфигурациях сенсорного элемента и его ориентации по отношению к акустическому полю. В качестве источника акустического воздействия использовался динамик с диаметром диафрагмы $40 \mathrm{~cm}$. Исследовались следующие варианты конфигураций: катушка из 4 витков ОВ диаметром 50 см с вертикальным размещением; катушка из 4 витков ОВ диаметром $50 \mathrm{~cm} \mathrm{с}$ горизонтальным размещением; прямой участок ОВ длиной $40 \mathrm{~cm}$, размещенный над диафрагмой динамика. Для акустической изоляции и предотвращения паразитных воздействий система опроса и чувствительной элемент с динамиком размещались в разных комнатах. К динамику подводился синусоидальный сигнал с частотой в диапазоне $500-10000$ Гц, при этом обеспечивался уровень акустического воздействия 60-70 дБа для диапазона 800 - 2400 кГц. Примеры результатов измерения для частоты 1.7 кГц приведены на рис. 3.
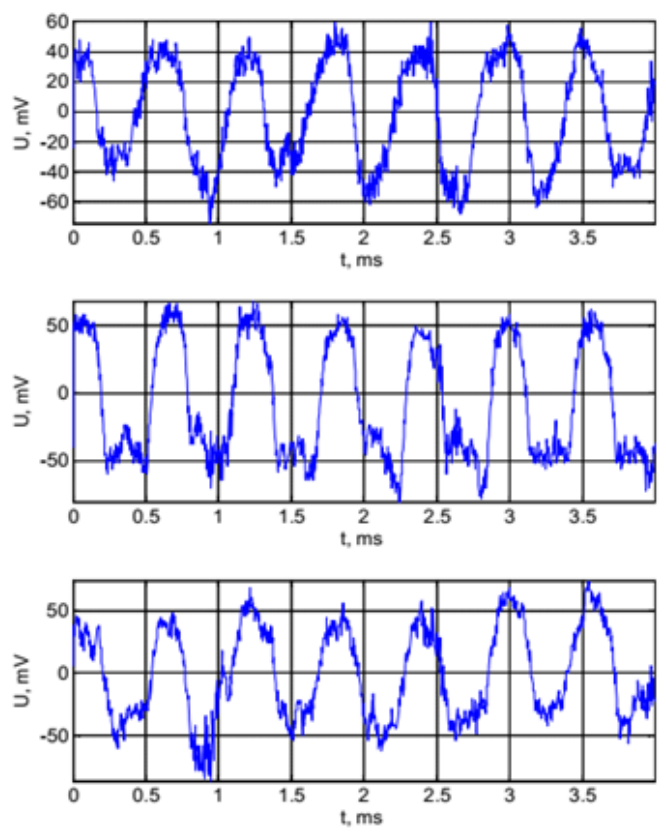

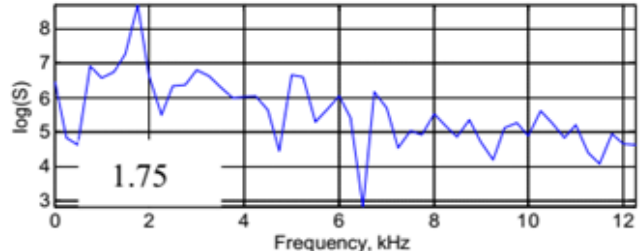

a)

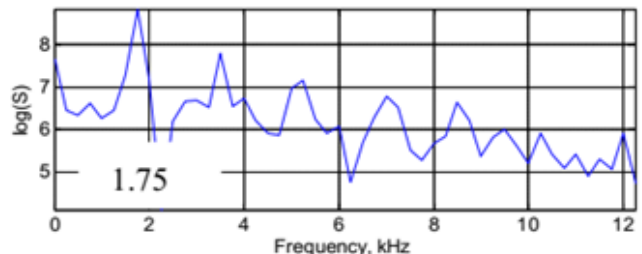

б)

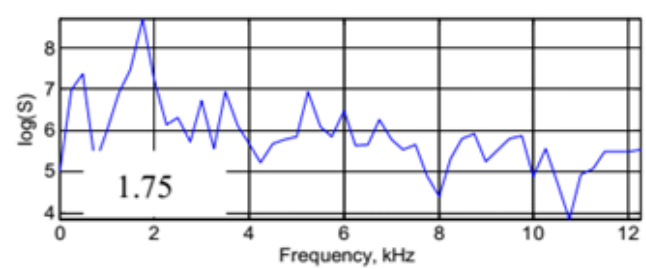

в)

Рис. 3. Детектированный сигнал и спектральные характеристики: а) катушка OB, горизонтальное размещение; б) катушка OB, вертикальное размещение; в) прямой участок ОВ

Таким образом, было продемонстрирована возможность выявления воздействия и определение его характеристик. При этом было отмечено, что амплитуда детектируемого сигнала в значительной степени зависит от установок модового контроллера и контроллера поляризации.

\section{Литература}

[1] M.R. Layton, J.A. Bucaro, Applied Optics 18 (5), 666-670 (1979)

[2] A. Kumar, N.K. Goel, R.K. Varshney, J. Lightwave Technology, 19 (3), 358-362 (2001)

[3] O.I. Kotov, G.B. Liokumovich, S.I. Markov, Proc. SPIE 5381, 91-102 (2004) 